Article

\title{
The Relevance of Political Stability on FDI: A VAR Analysis and ARDL Models for Selected Small, Developed, and Instability Threatened Economies
}

\author{
Petar Kurecic $^{1, *}$ and Filip Kokotovic ${ }^{2}$ \\ 1 Business and Economics Department, University North, Koprivnica 48000, Croatia \\ 2 University College of International Relations and Diplomacy Dag Hammarskjöld, Zagreb 10000, Croatia; \\ filip.kokotovic@hotmail.com \\ * Correspondence: pkurecic@unin.hr; Tel.: +38-598-980-8577 \\ Academic Editor: Eric Rougier
}

Received: 27 April 2017; Accepted: 13 June 2017; Published: 22 June 2017

\begin{abstract}
This paper studies the relevance of political stability on foreign direct investment (FDI) and the relevance of FDI on economic growth, in three panels. The first panel contains 11 very small economies; the second contains five well-developed and politically stable economies with highly positive FDI net inflows, while the third is a panel with economies that are prone to political violence or targeted by the terrorist attacks. We employ a Granger causality test and implement a vector autoregressive (VAR) framework within the panel setting. In order to test the sensitivity of the results and avoid robust errors, we employ an ARDL model for each of the countries within every panel. Based upon our results, we conclude that there is a long-term relationship between political stability and FDI for the panel of small economies, while we find no empiric evidence of such a relationship for both panels of larger and more developed economies. Similarly to the original hypothesis of Lucas (1990), we find that FDI outflows tend to go towards politically less stable countries. On the other hand, the empiric methodology employed did not find such conclusive evidence in the panels of politically more developed countries or in the small economies that this paper observes.
\end{abstract}

Keywords: political stability; VAR analysis; Granger causality test; investor confidence; ARDL analysis

JEL Classification: C32; C33; O1; F21

\section{Introduction}

Foreign direct investment (FDI) is considered an important motivator of economic growth. There are various studies that address the issue of the relevance of FDI to economic growth, comprising numerous other macroeconomic variables. As such, this study aims to fill the literature gap in understanding the psychological factor of macroeconomic dynamics as becoming increasingly important in determining the key components of economic growth. The approaches to identifying key trends are increasingly interdisciplinary, while intuitive claims and policy discussions should be accompanied by adequate quantitative analysis and empirical proof. This was especially obvious during the time of the 2008 crisis, as noted by Krugman (2009), who claims that investor confidence and their perceptions or prejudice currently are the key economic elements. In these times, perhaps, the issues of perception and investor's confidence are becoming increasingly important in maintaining stable economic growth. Perhaps a key element to the issue of public awareness is the media coverage, as indicated in several studies that point out the so-called "CNN effect". 
The "CNN effect"1 is perhaps far more important in the sphere of political science, sociology and journalism, but as this study will attempt to assess, it may have a profound effect on the economic situation (Gilboa 2005; Robinson 2005; Livingston and Eachus 1995). Instead, media coverage and public awareness of episodes of political violence is far more significant in larger countries where there is global public interest in the events unfolding. Thakur (2006) (p. 55) emphasizes that the United Nations officials attempted to negotiate with media representatives to further their coverage of episodes of political violence to make the American public opinion more inclined to foreign intervention. The importance of media coverage is not contained to the sphere of high politics and conflict management; it also may have significant impact on key economic indicators such as FDI. Thus, it is possible to approach the issue from two completely different initial hypotheses. One possible hypothesis is that there is a more profound effect of episodes of political violence in larger countries on economic growth and FDI. On the contrary, very small countries are not in the media spotlight. An alternative hypothesis may be that investors are not so much concerned with political stability in large countries and that political stability is far more relevant in small economies, where investors require political stability as an initial condition to consider such areas as the targets for investment. In this paper, we aim to consider both hypotheses, empirically and theoretically, and provide conclusions on which hypothesis is substantiated with more empiric evidence. Thus, the paper aims to understand the impact of political stability on FDI, while also engaging in a discussion on the impact of FDI on economic growth itself. By considering both of these aspects and by implementing several relevant quantitative approaches, we aim to understand the relevance of these factors for economic growth and find relevant policy implications. As will be emphasized in the literature review, we find that many studies are robust in considering panels of countries and cross-section data that do not take into account the economic development of the country, nor its political climate. In order to do so, the introduction will be followed by a short review of the existing literature. It will be followed by a discussion on the methodological approach of the paper. Furthermore, the paper will provide a theoretical discussion and summary of the results obtained from the empiric approach. Finally, the paper will provide relevant policy recommendations based upon the results.

\section{Literature Review}

Many researchers in finance and economics try to find the factors that affect FDI. An important element that needs to be mentioned is that, aside from the direct impact of FDI, there can also be a multiplier effect on economic growth. As emphasized by Ray (2012), FDI causes increased employment and productivity, enhanced technological improvements and boosts in exports. It is therefore important to notice that the empirical assessment of FDI can only take note of the direct (net) impact on economic growth, while it isn't fully able to capture the "spillover" or multiplier impact on the economy. Regardless, there have been numerous empiric research papers that analyze the impact of investments on economic growth.

For example, Lucas (1990) argues that only political risk is an important factor in limiting capital flows. Investments in many developing countries are exposed to large political risks, so FDI inflows are large for politically unstable countries. For the same reason, FDI outflows are large for politically stable countries to invest in countries with large political risks (Haksoon 2010, p. 59). From all sources that we have explored, Almfraji and Almsafir (2014) did the most comprehensive and systematized literature review on FDI effect on the economic growth from 1994 to 2012 that we came across. This review paper has concluded that the majority of papers suggest that there is a positive relationship between FDI and

1 Simply stated, the CNN effect states that there is a strong connection between the news that is covered and policy-making (Gilboa 2005). This can be extended to the sphere of global economics, despite the primary field of the CNN effect being journalism and political science, where the impact of TV coverage on policy-making is discussed. The way we attempt to do so is through understanding whether negative coverage of political events decreases investor confidence into these countries and thus, investments. 
economic growth, although they emphasize that there are instances where papers concluded that there was no, or even a negative, impact (Almfraji and Almsafir 2014). Our own literature review has found similar discrepancies in the existing literature.

\subsection{The Comparative Studies Explored}

Kholdy (1995) has examined ten East Asian countries and by implementing Granger causality tests determined that there is no causality between FDI and productivity, though this may be due to the nature of Granger causality tests, as later discussed in the methodology section. Balasubramanyam et al. (1996) concluded that FDI inflows are far more significant for countries that focus on export, rather than those who have a negative trade balance. In her study of foreign direct investments (FDI) in three regions of the South (South-East Asia, Sub-Saharan Africa, and Central America), McMillan (1999) studied the various patterns of FDI in the following countries: Thailand and the Philippines; Cote D'Ivoire and Ghana; Costa Rica and Guatemala). The author used Multivariate Granger Causality Tests on each country. The principal result of the comparisons is that the domestic context of FDI generates identifiable patterns of development outcomes. However, FDI is not the primary causal agent in development outcomes. The results support the contention that FDI was drawn in by a strong bargaining context, but that it is not itself a particularly strong determinant of domestic economic and political outcomes. Elkomy et al. (2016) have conducted their own empiric analysis upon 61 transition and developing countries for the period 1989 to 2013. The paper finds that there is no critical threshold of human capital requirement in order for the spillover effect of FDI to be achieved and further finds that domestic investments is a much more significant driving force in democratic countries (Elkomy et al. 2016).

The study of Bačić et al. (2004) focuses on the impact of FDI on economic growth in eleven transitional countries. Their conclusion is that there is a statistically significant positive impact of FDI inflows in small countries, such as Slovenia, Slovakia and Lithuania, yet the impact was far more pronounced in more developed countries (Bačić et al. 2004). Similarly, Asteriou et al. (2005) focus on the impact of FDI on economic growth of ten European transition countries. Their main conclusion is the existence of a positive correlation between FDI and economic growth, yet they also detect a negative correlation between portfolio investments and economic growth (Asteriou et al. 2005). Brada et al. (2005) studied the effects of transition and political instability on foreign direct investment in ECE and found the fact that they were countries in transition enabled those increased FDI inflows in comparison with West European countries. This somewhat contrasts the findings of Elkomy et al. (2016), who find that there is no impact of FDI on economic growth in transitional countries.

Haksoon (2010) in his study of the influence of political stability on FDI suggests two hypotheses, with the first being that FDI inflows generally flow towards countries that suffer from instances of political instability, while FDI inflows tend to flow from politically stable countries. Haksoon (2010) second hypothesis is that, after adjusting for macroeconomic factors, the inwards performance of FDI is high for countries that suffer from instances of political instability. He managed to confirm both hypotheses with an emphasis that this conforms to the findings of Lucas (1990). These findings suggest that there is an increased level of FDI towards countries that have a higher level of political corruption and suffer from instances of political instability (Haksoon 2010). A pooled ordinary least squares (OLS) with robust standard errors for the panel data using robust (cluster) covariance matrix as in Wooldridge (2002), was performed first with several other quantitative method analysis to confirm the hypotheses. Khan and Mashque (2013) determine a negative and significant relationship between political risk and FDI, accounting for 94 countries over a span of 24 years from 1986-2009. They conclude that most of the political risk indicators have a negative relationship with FDI for the world as a whole and the high-income countries but the relationship was the strongest for the upper middle-income countries.

Iamsiraroj and Doucouliagos (2015) study the success of economic growth in attracting FDI. Meta-regression analysis is applied to 946 estimates from 140 empirical studies. The authors show 
that there is a robust positive correlation between growth and FDI. Significantly, larger correlations are established for single country case studies than with cross-country analysis. Čičak and Sorić (2015) study the impact of FDI inflows on economic growth in Croatia and other selected transition economies by implementing a VAR approach. The key conclusion of the paper is that there is evidence of Granger causality going from FDI towards economic growth (Čičak and Sorić 2015). Another significant aspect is that Čičak and Sorić (2015) determine that, based on their results for Latvia and Slovenia, investor confidence is increased in case of a more stable macroeconomic environment.

Mehrara et al. (2010) employed a panel data approach to a sample of 57 developing countries in which they determined that there is a short-run causality from FDI net inflows and exports to GDP. Several studies mention the relevance of political factors to FDI, such as Büthe and Milner (2008) who start with a standard economic model as follows:

$$
\begin{gathered}
F D I_{(i, t)}=\alpha+\gamma_{1}(\text { Market Size })_{i,(t-1)}+\gamma_{2}(\text { Econ. Development })_{i,(t-1)}+ \\
\gamma_{3}(\text { GDP growth })_{i,(t-1)}+\delta_{1}+\varepsilon_{i, t}
\end{gathered}
$$

where FDI is the natural logarithm of the values of foreign direct investment, market size is the natural logarithm of the values of population, Econ. Development is the log of per capita GDP; GDP growth proxies economic growth; $\delta_{1}$ is a country fixed dummy variable, and $\alpha$ is the constant and $\varepsilon$ is the error term.

To this simple model, they added several political variables, notably bilateral investment treaties, GATT/WTO membership, domestic political constraints and political instability (Büthe and Milner 2008, p. 750). They conclude that adding each variable improves the explanatory value of the model and it is interesting to note that they find a slightly, but statistically significant negative effect of political instability on FDI (Büthe and Milner 2008). Bisson (2011) (Bisson) employed an OLS regression to determine that the relevance of several variables used as proxies for political instability were statistically significant to a cross-section group of 45 selected developing countries. Jadhav (2012) conducted a panel regression approach to the BRICS countries from 2000-2009, using the following empiric strategy:

$$
\begin{gathered}
F D I_{i t}=\alpha+\beta_{1} M S_{i t}+\beta_{2} N R A_{i t}+\theta(\text { Institutional Variables })_{i t}+ \\
\mu(\text { Policy Variable })_{i, t}+\varphi(\text { Political Risk Variable })_{i t}+\varepsilon_{i, t}
\end{gathered}
$$

where $F D I$ is foreign direct investment, MS measures market size, NRA is the Natural resource availability, $\theta$ measures Corruption, Rule of Law, Voice and Accountability, $\mu$ accounts for the Inflation rate and the Trade to-GDP ratio, $\varphi$ accounts for Political Stability and No Violence, Government Effectiveness, Regulatory Quality, with the constant $\alpha$, while the error term is represented by $\varepsilon$.

By using such an empiric strategy, Jadhav (2012) (pp. 11-12) failed to obtain statistically significant results, even at the $10 \%$ level of significance, for the variables that concern political stability and rule of law, while voice and accountability was statistically significantly negatively associated with FDI. Busse and Hefeker (2005) implemented a panel GMM approach to a series of variables that measure political stability and the quality of government and concluded that government stability, the absence of internal conflict and ethnic tensions, basic democratic rights and ensuring law and order have a statistically significant effect on FDI. As emphasized by her detailed literature review, Pandya (2016) finds that many countries have become more open to FDI through an increase in the volume of trade and trade agreements, deregulation, as well as investment incentives.

\subsection{Selected Studies of Single Economies Explored}

Onwuka and Zoral (2009) studied the long-term relationship between FDI and import growth in Turkey. The authors include both the traditional import demand function with the inclusion of FDI, as well as an ARDL and FMOLS approach to confirm their hypothesis and avoid the possibility of 
robust errors. Akande and Oluyomi (2010) explored the relevance and application of the theoretical prescriptions of the Two-Gap model to the Nigerian economic growth situation from 1970 to 2007. A co-integration test confirmed that a long-running relationship exists among the variables, giving an indication that they have the tendency to reach equilibrium in the long run.

Al-Eitan (2013) studied the influence of FDI on economic growth in Jordan, from 1996 to 2010, using several quantitative methods such as VAR models and Granger causality. Based on the analysis, the results showed that Jordan economic risk, the price of stock market sectors and two of the macroeconomic variables (inflation and GDP) significantly caused inward FDI in Jordan. Aga (2014) studies the impact of FDI on economic growth on the example of Turkey for the 1980-2012 periods. The paper utilizes the Johansen co-integration test whereby it finds no co-integration and long run relationship between variables.

\subsection{Summary of Literature Review and Implications}

As was previously pointed out in Almfraji and Almsafir (2014), there are a number of significant discrepancies in the existing literature. Most significantly, there is no clear consensus on whether there is a positive impact of FDI on economic growth. Furthermore, there is a lack of consensus on whether or not the relationship is significant in only the short-term or whether there is a long-term relationship between the two variables. For the purpose of this paper, the results of two papers have perhaps the most significant implications. Primarily, this is the finding of Haksoon (2010) that complies with the theory of Lucas (1990) that there is an increased level of FDI inflows into countries that are impacted by political corruption and instability. On the other hand, Jadhav (2012) finds no evidence of any impact of political stability and rule of law on FDI. All of these findings will be considered (Büthe and Milner 2008; Jadhav 2012; and Čičak and Sorić 2015) and discussed upon evaluating our empiric results. Prior to conducting our empiric analysis, we discuss in detail our methodological approach.

\section{Methodology}

The data employed for the empiric analysis was extracted from the World Bank (2016) database, the values of GDP in current dollars and the net inflow of FDI in current dollars and for the export of goods and services in current dollars for the period of 1996-2014. The data was then corrected for inflation using the GDP deflator, also acquired from the World Bank (2016) database. ${ }^{2}$ The data was also extracted for population of each country, as well as the arable land available, measured in thousands of hectares. The variable that concerns political stability was obtained from the dataset constructed by Kaufmann et al. (2010). Their index ranges from -2.5 to +2.5 for the considered variables-political stability and the absence of violence/terrorism. Higher values of this index indicate a higher level of political stability, while lower levels indicate a diminished level of political stability and more frequent occurrences of violence, as well as terrorist attacks. We consider three different panels, a panel of small economies, a panel of developed western economies and a panel of economies that are known for issues regarding political violence or are frequently targeted by terrorists. Exact specifications of the panels are available in the Appendix A, while the panels are further referred to as panel A for the panel of small economies, panel B for the panel of developed economies and panel $C$ for the panel of countries that have issues regarding political violence and terrorist attacks, respectively. A significant benefit of such a panel specification was that, in the observed period, the FDI inflow values for the majority of the considered countries were positive. This allows the paper to focus on substantial issues regarding the effect of political stability on FDI inflows without resorting to methods sometimes considered controversial. ${ }^{3}$ The countries were divided into three separate panels, as specified in

2 Using the formula GDP $\mathrm{t} \times$ GDP deflator base year/GDP deflator $\mathrm{t}$ where the base year was the value of the GDP deflator for the last year where the data was available - in most cases, 2014 and $t$ are the years for which the GDP data was available.

3 There are two possible solutions when considering negative FDI inflows. Not using logged versions of the variables probably results in heteroscedasticity issues, amongst others. Thus, two solutions are possible: considering the negative 
Table A1 in the Appendix A. The states that were put into the three different panels (small economies, large developed economies, and economies that were threatened by terrorist attacks or instances of political instability) were chosen arbitrarily, albeit with certain prerequisites. Of the 11 small economies that were studied, eight were small island economies (six from the Caribbean), and three were small African economies.

Developed economies that were studied represent some of the most developed economies, and at the same time all of them are among the 15 largest economies of the world, being members of the Triad (North America-the EU-Asia-Pacific Rim region), as the core of the world economy, although its relative "weight" in the world economy is slowly declining. In 2014, Australia was the 12th economy of the world, Canada 11th, France 6th, United Kingdom 5th, and the United States 1st. The economies of the countries that have issues regarding political violence and terrorist attacks were studied through four examples that were placed in panel C: Mexico (due to the anti-drug warfare mostly), Israel, the Russian Federation, and Turkey. The panels are therefore clearly separated by size-panel A consists of small economies in comparison to B and C.

The panels also are differentiated based on political stability that is essential to FDI inflows, although the literature review does not provide conclusive evidence on how political stability will impact our final results. All of the countries that are included in panel $C$ have consistently negative values for political stability based on the index created by Kaufmann et al. (2010) and this is the primary determinant of this panel. As many papers have previously stated, it is slightly difficult to determine the smallness of the economy, but all of the countries that are used in panel A have either comparatively small populations in regards to panels B and C, as well as economic growth that seems insignificant when compared to the values in panels B and C. A full list of these countries is presented in the Appendix A.

Before considering further quantitative methods of analysis, several unit root tests will be used to test for the presence of unit root. This will be conducted by using the tests originally proposed by Levin et al. (2002), as well as Im et al. (2003), and augmented versions of the test proposed by Phillips and Perron (1988) and Dickey and Fuller (1979). All of these tests are conducted against the null hypothesis of a unit root present and are conducted by an autoregressive procedure based upon a suitable number of lags. The number of lags is determined by the information criterion proposed by Schwarz (1978). Selected summary statistics for all of the variables, in level and without any statistical transformation, are available in the Appendix A, as Table A2. In our empiric approach, the variables that measure economic growth, exports, as well as FDI will always be considered in the form of their natural logarithm after we have corrected the values for inflation. After conducting the unit root tests the following three-step empiric strategy is considered.

\subsection{Panel Model}

Following the results of the conducted panel root test, we will estimate a test for causality between FDI, political stability and absence of violence/terrorism and GDP for each of the panels, by using the test initially proposed by Granger (1969). The Granger causality test is conducted by running a bivariate regression, which displays whether adding lagged versions of a variable helps explain the behavior of the independent variable. Therefore, the test will be conducted in the following form:

$$
\begin{aligned}
& Y_{i, t}=\alpha_{0, i}+\alpha_{1,1} Y_{i, t-1}+\ldots+\alpha_{1, i} Y_{1, t-1}+\beta_{1, i} X_{i, t-1}+\ldots+\beta_{1, i} X_{1,-1}+\ldots+\epsilon_{i, t} \\
& X_{i, t}=\alpha_{0, i}+\alpha_{1,1} X_{i, t-1}+\ldots+\alpha_{1, i} X_{1, t-1}+\beta_{1, i} Y_{i, t-1}+\ldots+\beta_{1, i} Y_{1,-1}+\ldots+\epsilon_{i, t}
\end{aligned}
$$

values as NA-s or adding an arbitrary constant. As we find, the first approach unacceptable and accept that the second is not considered adequate universally, the suggested panel specification seems like the best approach to focus on the substantial issues of this paper. 
where $\mathrm{X}, \mathrm{Y}$ are the variables observed in the regression, ${ }^{4} \alpha_{0, \mathrm{i}}$ is the constant, $\epsilon_{\mathrm{i}, \mathrm{t}}$ : is the error term and $\alpha_{1 . . l}$ and $\beta_{1 . . l}$ are the coefficients.

The Granger causality test is then conducted by estimating the Wald test for the significance of the joint hypothesis:

$$
\beta_{1}=\beta_{2}=\ldots=\beta_{1}=0 .
$$

In accordance with Granger (1969) initial methodology, the null hypothesis is therefore that there is no Granger causality between the variables. Rejection of the null hypothesis at the observed significance levels implies a statistically significant causal relationship.

\subsection{Vector Auto Regression}

Following the Granger causality test, we will conduct a Vector auto regression (VAR) model. The model is in detail specified in Equation (4):

$$
\begin{gathered}
F D I_{t}=\alpha_{0}+\alpha_{1} F D I_{t-1}+\ldots+\alpha_{1,2} F I_{t-n}+\alpha_{2} Y_{t-1}+\ldots+\alpha_{2,1} Y_{t-n}+\alpha_{3} P O L_{t-1}+\ldots+ \\
\alpha_{3,1} P_{t-n}+\alpha_{4} C_{t}+\varepsilon_{t, 1}, \\
P O L_{t}=\beta_{0}+\beta_{1} F D I_{t-1}+\ldots+\beta_{1,2} F D I_{t-n}+\beta_{2} Y_{t-1}+\ldots+\beta_{2,1} Y_{t-n}+\beta_{3} P O L_{t-1}+\ldots+ \\
\beta_{3,1} P O L_{t-n}+\beta_{4} C_{t}+\varepsilon_{t, 2} \\
Y_{t}=\gamma_{0}+\gamma_{1} F D I_{t-1}+\ldots+\gamma_{1,2} F D I_{t-n}+\gamma_{2} Y_{t-1}+\ldots+\gamma_{2,1} Y_{t-n}+\gamma_{3} P O L_{t-1}+\ldots+ \\
\gamma_{3,1} P_{t-n}+\gamma_{4} C_{t}+\varepsilon_{t, 3},
\end{gathered}
$$

where FDI is the log of foreign direct investment, $Y$ is the log of real GDP, $P O L$ is the variable that accounts for political stability and absence of violence/terrorism, $C$ is the exogenous control variable; $\alpha_{1 . .4}, \beta_{1 . .4}, \gamma_{1 . .4}$ are the coefficients, $\alpha_{0}, \beta_{0}, \gamma_{0}$ are the constants, while $\varepsilon_{1 . .3}$ represents the vector of innovation.

This model will provide us with a more detailed understanding of the variables that are relevant to the increase of FDI. Primarily the interest of this paper is the impact of GDP and political stability and absence of violence/terrorism. We consider the variables Foreign Direct Investment (FDI), Gross Domestic Product (GDP) and political stability (POL) endogenous to the model. The remaining variable serves as a control variable that increases the explanatory value of the model. These potential control variables are the logged values of exports of goods and services (Exp), logged values of total population in thousands (Pop) and logged values of arable land in hectares (Land). The abbreviations in the parenthesis will be used in conducting all further aspects of our empiric methodology. One of these three variables will be selected based upon stepwise regression, through the value of the test statistic, in order to maximize the explanatory value of the model. We consider that all of these variables may have a statistically significant impact on FDI inflow, yet they are only control variables and will therefore not be discussed in detail, as they are not the primary focus of this study. This VAR is conducted by using OLS on the pooled data. The VAR framework is used primarily to understand the impulse response of each of the selected panels and further study will be conducted on each of the individual countries to test the relevance of any hypothesis gathered from both the Granger causality test and the VAR model. The lag length for each of the VAR models will be determined using the information criterion proposed by Akaike (1974). The specification tests will consider whether there is serial correlation between the residuals based upon the LM test, which was constructed based upon the research by Breusch (1978) and Godfrey (1978). They shall also determine whether the VAR models conform to the stability condition.

4 In the case of our model, we examine causality between three variables-FDI, GDP and political stability and absence of violence/terrorism. 


\subsection{ARDL Models}

In order to check the validity of our previous results and as an additional sensitivity check, we will conduct autoregressive distributed lag (ARDL) analysis, proposed initially by Pesaran and Shin (1999), on each of the countries. The ARDL method has several significant advantages, notably the fact that we can use different lag lengths of the dependent and independent variables. Perhaps the greatest advantage of the ARDL approach is that it can be used on both $\mathrm{I}(0)$ and $\mathrm{I}(1)$ variables, while, for instance, traditional co-integration processes require both variables to be $\mathrm{I}(1)$ and the majority of standard regression processes require stationarity. If any variable is determined to be I(2) or higher, the ARDL method cannot and will not be employed. The presence of a unit root is tested by conducting tests proposed by Dickey and Fuller (1979) and by Kwiatkowski et al. (1992). These tests will allow us to determine whether the ARDL analysis may be used for all of the models.

After estimating the correct number of lags based upon the Akaike information criterion, we first implement tests to confirm heteroscedasticity initially proposed by Breusch and Pagan (1979), the absence of serial correlation based upon the LM test and the tests of stability of the parameters based upon the work of Page (1954) and Barnard (1959) will be conducted, although they will not be presented in the paper. Once the models are properly estimated, we implement the Bounds test devised by Pesaran et al. (2001) in order to estimate whether there is a long-term relationship between the variables. We estimate two models: in the first model GDP is the dependent variable, FDI the independent variable, while in the second FDI is the dependent variable, and political stability is the independent variable. If the results of the Bounds test suggest we can reject the null hypothesis, we estimate the long-term coefficients.

\subsection{Methodological and Data Constraints}

A significant constraint of using the Granger causality method or rather any method in a panel setting is not taking into account possible robust errors. This is the reason why we chose to employ an ARDL model for each of the countries within the panel. The panel selection is subject to research bias and while the panels were not completely arbitrarily constructed, the method of selection may cause specification errors. Panel $C$ is especially heterogeneous regarding numerous economic and political traits of the countries considered in the panel. Aside from the previously identified issues, the Granger causality test suffers from other issues that warranted the use of multiple empiric tests. Maziarz (2015) emphasizes that both log transformations and modifications of variables to ensure their stationarity may cause potential errors with Granger's causality test. He further points out that this test is completely dependent upon Granger's definition of causality, which is why the largest number of studies correctly reference this causality as "Granger-cause" (Maziarz 2015). Another problem that is emphasized is that there may be a third variable that might Granger-cause both variables, but such a case may lead to a false causality result (Maziarz 2015).

A significant data constrain was that data for the political stability and absence of violence/terrorism error was only available for the period 1996-2014, excluding 1997, 1999 and $2001 .^{5}$ On the other hand, we believe that that the variable we use to proxy for political stability constructed by Kaufmann et al. (2010) is perhaps the most objective assessment of political stability. Thus, we accept the limited period in order to obtain the desired results.

\section{Discussion and Results}

In adherence with the previously described methodology, we first employ a series of panel unit root tests to determine whether there is a unit root present. Based upon our analysis of the previewed data, we conclude that the test with constant and without trend is adequate. The only variable where

5 The data for the years 1997, 1999 and 2001 was generated by averaging the values of the values for $t-1$ and $t+1$, meaning that for the year 1997 the average value of the index for 1996 and 1998 was calculated. 
a linear trend was included was for the variable political stability in panel $\mathrm{C}$. In order to obtain the statistically most adequate results, only variables where all four conducted tests reject the null hypothesis of unit root presence at the 5\% significance level are deemed stationary. As previously mentioned, the number of lags was identified based upon the criterion proposed by Schwarz (1978). When the variable was not stationary in level, the value of the test statistic for the difference in which the variable was stationary is presented in Table 1.

Table 1. Unit root tests.

\begin{tabular}{|c|c|c|c|c|c|c|}
\hline & Variable & $\begin{array}{c}\text { Levin, Lin and } \\
\text { Chu } t\end{array}$ & $\begin{array}{l}\text { Im, Pesaran and } \\
\text { Schin W-stat }\end{array}$ & $\begin{array}{l}\text { ADF-Fischer Chi } \\
\text { Square }\end{array}$ & $\begin{array}{l}\text { PP-Fischer Chi } \\
\text { Square }\end{array}$ & Conclusion \\
\hline \multirow{5}{*}{ GDP } & Panel A & $-5.796^{* *}(0.0000)$ & $-1.886 *(0.0297)$ & $35.471 *(0.0346)$ & $33.55(0.0545)$ & $\mathrm{I}(1)$ \\
\hline & In first difference & $-9.604 * *(0.0000)$ & $-9.206 * *(0.0000)$ & $125.55 * *(0.0000)$ & $143.425 * *(0.0000)$ & \\
\hline & Panel B & $0.078(0.5311)$ & $3.215(0.9993)$ & $1.147(0.9997)$ & $0.9334(0.9999)$ & $\mathrm{I}(1)$ \\
\hline & In first difference & $-8.158^{* *}(0.0000)$ & $-7.446(0.0000)$ & $67.342(0.0000)$ & $65.938(0.0000)$ & \\
\hline & Panel C & $-8.705 * *(0.0000)$ & $-12.653 * *(0.0000)$ & $117.31 * *(0.0000)$ & $108.929 * *(0.0000)$ & $\mathrm{I}(0)$ \\
\hline \multirow{4}{*}{ FDI } & Panel A & $-5.421^{* *}(0.0000)$ & $-5.001 * *(0.0000)$ & $63.3486^{* *}(0.0000)$ & $72.883^{* *}(0.0000)$ & $\mathrm{I}(0)$ \\
\hline & Panel B & $-2.021 *(0.0216)$ & $-1.565(0.0588)$ & $15.54(0.1136)$ & $14.113(0.1679)$ & $\mathrm{I}(1)$ \\
\hline & In first difference & $-11.932 * *(0.0000)$ & $-12.618^{* *}(0.0000)$ & $118.22 * *(0.0000)$ & $107.06^{* *}(0.0000)$ & \\
\hline & Panel C & $-3.958 * *(0.0000)$ & $-4.647^{* *}(0.0000)$ & $37.947^{* *}(0.0000)$ & $43.809 * *(0.0000)$ & $\mathrm{I}(0)$ \\
\hline \multirow{4}{*}{ Exp } & Panel A & $-3.175^{* *}(0.0007)$ & $-2.529 * *(0.0057)$ & $42.838^{* *}(0.0049)$ & $45.155^{* *}(0.0025)$ & $\mathrm{I}(0)$ \\
\hline & Panel B & $0.7669(0.7784)$ & $3.112(0.9991)$ & $0.9644(0.9999)$ & $0.87092(0.9999)$ & $\mathrm{I}(1)$ \\
\hline & In first difference & $-9.961^{* *}(0.0000)$ & $-9.58^{* *}(0.0000)$ & $89.2926^{* *}(0.0000)$ & $116.361 * *(0.0000)$ & \\
\hline & Panel C & $-8.723 * *(0.0000)$ & $-7.386 * *(0.0000)$ & $64.405^{* *}(0.0000)$ & $57.447 * *(0.0000)$ & $\mathrm{I}(0)$ \\
\hline \multirow{3}{*}{ Pol } & Panel A & $-2.9711^{* *}(0.0015)$ & $-2.7115^{* *}(0.0033)$ & 41.521 ** $(0.0071)$ & $39.909 *(0.0111)$ & $\mathrm{I}(0)$ \\
\hline & Panel B & $-1.761 *(0.0391)$ & $-1.679 *(0.0466)$ & $10.44 *(0.0336)$ & $9.636 *(0.047)$ & $\mathrm{I}(0)$ \\
\hline & Panel C & $-5.0694 * *(0.0000)$ & $-2.692 * *(0.0036)$ & $28.21 * *(0.0004)$ & $271.71^{* *}(0.0000)$ & $\mathrm{I}(0)$ \\
\hline \multirow{5}{*}{ Pop } & Panel A & $0.0599(0.5239)$ & $1.0002(0.8414)$ & $22.141(0.4515)$ & $56.4981 * *(0.0001)$ & $\mathrm{I}(2)$ \\
\hline & In second difference & $-6.474^{* *}(0.0000)$ & $-5.566 * *(0.0000)$ & $83.12 * *(0.0000)$ & $48.604^{* *}(0.0000)$ & \\
\hline & Panel B & $-0.3597(0.3595)$ & $4.557(1.000)$ & $3.796(0.9561)$ & $1.56(0.9987)$ & $\mathrm{I}(2)$ \\
\hline & In second difference & $-9.787^{* *}(0.0000)$ & $-9.488^{* *}(0.0000)$ & $91.967^{* *}(0.0000)$ & $94.309(0.0000)$ & \\
\hline & Panel C & $-4.713^{* *}(0.0000)$ & $-3.217 * *(0.0006)$ & $31.882 * *(0.0001)$ & $65.426 * *(0.0000)$ & $\mathrm{I}(0)$ \\
\hline \multirow{6}{*}{ Land } & Panel A & $0.043(0.5173)$ & $-0.501(0.3081)$ & $13.965(0.6013)$ & $13.598(0.6287)$ & $\mathrm{I}(1)$ \\
\hline & In first difference & $-9.091 * *(0.0000)$ & $-10.813^{* *}(0.0000)$ & $128.805^{* *}(0.0000)$ & $129.657(0.0000)$ & \\
\hline & Panel B & $1.67(0.9525)$ & $0.421(0.6632)$ & $11.43(0.325)$ & $14.137(0.1668)$ & $\mathrm{I}(1)$ \\
\hline & In first differe & & & & & \\
\hline & Panel C & $-1.537(0.0621)$ & $0.244(0.5964)$ & $11.154(0.1931)$ & $10.834(0.2113)$ & $\mathrm{I}(1)$ \\
\hline & In first difference & $-6.416^{* *}(0.0000)$ & $-7.379 * *(0.0000)$ & 60.041 ** $(0.0000)$ & $59.721 * *(0.0000)$ & \\
\hline
\end{tabular}

Note: values in the parenthesis represent the $p$ value. ${ }^{*}$ and ${ }^{* *}$ indicate statistical significance at the respected 0.05 and 0.01 levels of significance.

For the variable political stability, we reject the presence of a unit root in all three panels. ${ }^{6}$ Regarding the other variables, GDP for panels A and B, FDI for panel B and export for panel B failed to reject the null hypothesis of a unit root present in level—but, in the first difference, they reject the null hypothesis at the $1 \%$ significance level. We find that arable land rejects the null of unit root in the first difference, while population in both panel $\mathrm{A}$ and panel $\mathrm{B}$ rejects the unit root null hypothesis in the second difference, while, in panel $C$, it is stationary in level. The remaining variables were already stationary at a level with only the log transformations being applied. Furthermore, unless explicitly specified otherwise, the variables are always considered in the transformed form in which they rejected the null hypothesis of unit root presence. The results of the Granger causality test are presented in Table 2.

6 This is also the only variable to which no log transformation, or any other statistical transformation, had been applied. 
Table 2. Granger causality test.

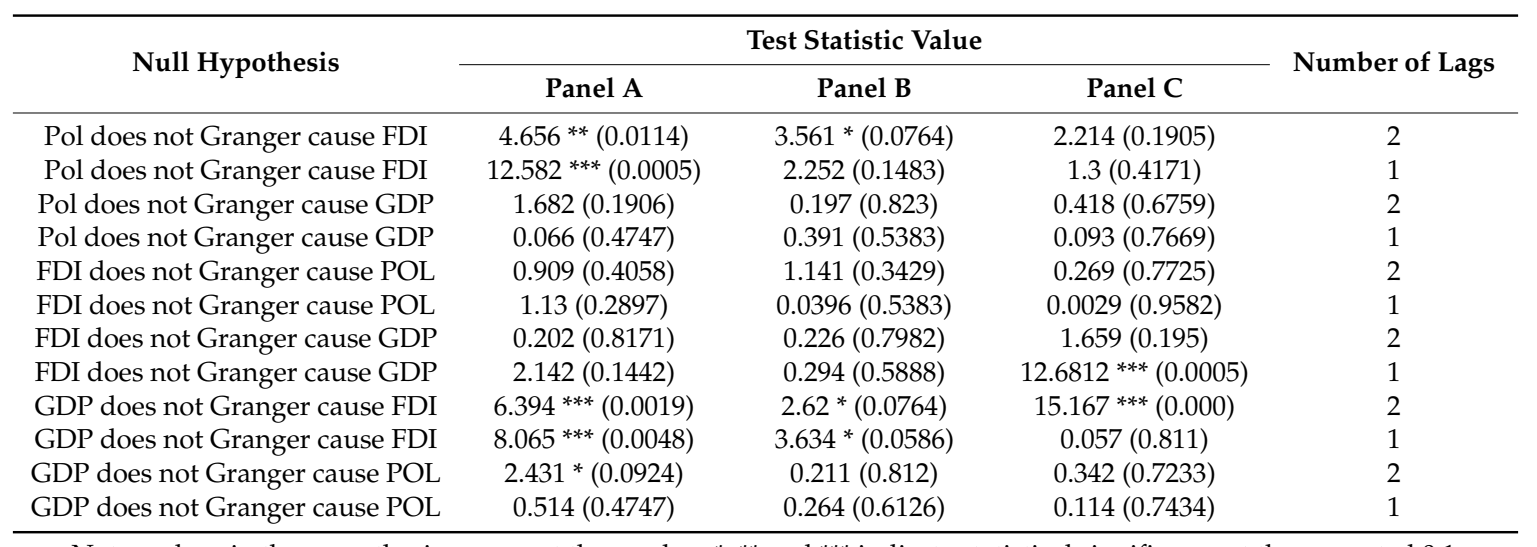

Note: values in the parenthesis represent the $p$ value. ${ }^{*}{ }^{* *}$ and ${ }^{* * *}$ indicate statistical significance at the respected 0.1 , 0.05 , and 0.01 levels of significance.

Granger panel causality tests, especially when preformed with as stacked tests, may be prone to robust errors as was previously mentioned in the methodological and data constrains. Therefore, any conclusions based upon these results should be taken with caution. So far, it is possible to determine that there is empiric evidence that political stability is more relevant in smaller economies where we determine that there is a unidirectional causal relationship going from political stability to FDI. The results for panel A also have the largest value of the test statistic in regards to higher values of GDP Granger causing an increase of FDI. This is a relatively intuitive conclusion as higher GDP values are often associated with economic growth that is accompanied by a pro-investment climate and favorable other macroeconomic indicators may increase investor confidence and thus increase FDI. In the remaining panels, we fail to determine any causal relationship between political stability with either GDP or FDI at the 5\% statistical significance level. As the result is only significant at the $10 \%$ significance level for panel $\mathrm{B}$, we will discuss this issue further in the continuation of the paper after conducting further tests. For panel B, we also find unidirectional Granger causality going from GDP to FDI, while, in this initial phase of testing, it is difficult to make a conclusive argument regarding panel C.

We include higher numbers of lags ${ }^{7}$ and with that specification, we detect bidirectional causality between FDI and GDP at three lags, but we find that the relationship is unidirectional going from GDP to FDI when using a higher number of lags. Similar to the situation regarding panel B, we will refrain from making any conclusions before conducting further tests. While the information criterion proposed by Schwarz indicates that one lag is optimal, the criterion proposed by Akaike (1974) suggests that two lags are optimal. These results suggest that the results obtained with two lags are the most accurate, as they repeat at higher instances of lags, but at this point, it is not possible to confirm that the causal relationship is unidirectional going from GDP to FDI. The extreme heterogeneity of the countries in the panel also prevents us from confirming such a conclusion at this time.

\subsection{VAR Model Approach}

The second quantitative research method employed is a VAR approach, as specified in the methodological discussion. The VAR approach will primarily be used to identify the Cholesky impulse response in order to better understand the relationship between FDI and GDP; as well as political stability and FDI. While the conclusions from the Granger causality test are noted, they did not have any impact on the specification of the VAR model. As the coefficient results are not being considered,

7 Test results for the panel C Granger causality test with three lags, as well as a short discussion about the results, are available in the Appendix A. 
Table 3 provides brief summary statistics of the descriptive value and relevant statistics of the model, while specification tests are provided in the Appendix A. Briefly, it is possible to confirm that the models are adequately specified as no root lies outside the unit circle. It is also possible to confirm that the residuals are not serially correlated, with the values of the LM test for each model in the Appendix A.

Table 3. Summary of significant statistics for VAR models.

\begin{tabular}{|c|c|c|c|c|c|c|}
\hline $\begin{array}{c}\text { Dependant } \\
\text { Variable }\end{array}$ & $R$-Squared & $\begin{array}{c}\text { Adjusted } \\
\text { R-Squared }\end{array}$ & $\begin{array}{c}\text { S.E. } \\
\text { Equation }\end{array}$ & F-Statistic & $\begin{array}{c}\text { Akaike } \\
\text { AIC }\end{array}$ & $\begin{array}{c}\text { Number of } \\
\text { Lags }\end{array}$ \\
\hline \multicolumn{7}{|c|}{ Panel A } \\
\hline GDP & 0.17 & 0.08 & 0.586 & 1.95 & -2.15 & \multirow{3}{*}{3} \\
\hline FDI & 0.816 & 0.796 & 0.649 & 42.051 & 2.07 & \\
\hline POL & 0.944 & 0.939 & 0.195 & 161.34 & -0.33 & \\
\hline \multicolumn{7}{|c|}{ Panel B } \\
\hline GDP & 0.801 & 0.581 & 0.029 & 3.63 & -3.92 & \multirow{3}{*}{3} \\
\hline FDI & 0.778 & 0.532 & 0.424 & 3.158 & 1.422 & \\
\hline POL & 0.616 & 0.19 & 0.199 & 0.149 & -0.671 & \\
\hline \multicolumn{7}{|c|}{ Panel C } \\
\hline GDP & 0.34 & -0.04 & 0.271 & 4.683 & -1.937 & \multirow{3}{*}{1} \\
\hline FDI & 0.728 & 0.573 & 0.045 & 0.901 & 0.519 & \\
\hline POL & 0.916 & 0.868 & 0.079 & 19.105 & -3.048 & \\
\hline
\end{tabular}

Aside from the endogenous variables, using stepwise regression, it was concluded that export of goods and services would mostly enhance the explanatory value for each of the models, while population and arable land were deemed to have a statistically insignificant effect. Exports are considered exogenous for each model. For panel A, based upon the Akaike info criterion, three lags should be used and as with that lag length there is no evidence of models miss-specification, three lags were used. For panel B, four lags were suggested but at four lags, the model does not satisfy the stability condition. At three lags, the stability condition is satisfied and the LM test rejects the presence of autocorrelation. For panel C, two lags were suggested. However, at such a specification, the model did not satisfy the stability condition. When the model was specified using one lag, it satisfied the stability condition and did not exhibit signs of autocorrelation.

The results from the Cholesky impulse function in Figure 1 regarding these two variables largely confirm the results obtained from the Granger causality tests. As we can see in panel A, the response is initially highly positive, with a slightly declining trend in the long term. It should be noted that, for panel B and panel C, 10 periods were used, while for panel A, 15 periods were used. The reason for this arbitrary change is the fact that the authors wished to consider the response after 10 periods in panel A to see whether the trend will continue to decline. Therefore, it is possible to conclude that there are significant differences between the Cholesky impulse response function to the introduction of one standard deviation of political stability to FDI between panel A, and panels B and C. The response for panel B seems spurious, which is logical when taking into account that these are highly developed economies that are not likely to be affected by occasional terrorist attacks or isolated episodes of political violence. Taking into account the findings by the Granger causality test, it is possible to confirm that a statistically significant consistent link between FDI and political stability for panel $\mathrm{B}$ does not exist. The response for panel $\mathrm{C}$ has the smallest initial response and it starts to decline strongly after three periods until and seems to have a marginal impact at around 6 periods. The results seem to indicate that political stability is relevant to FDI both short-term and long-term in panel A, only relevant in the short-term for panel $\mathrm{C}$, while it seems to have no statistically significant value for panel B. It is once again possible to observe significant differences between the three panels in Figure 2, as in panel $\mathrm{A}$ the impact becomes negative after two periods and no longer becomes positive after that. 

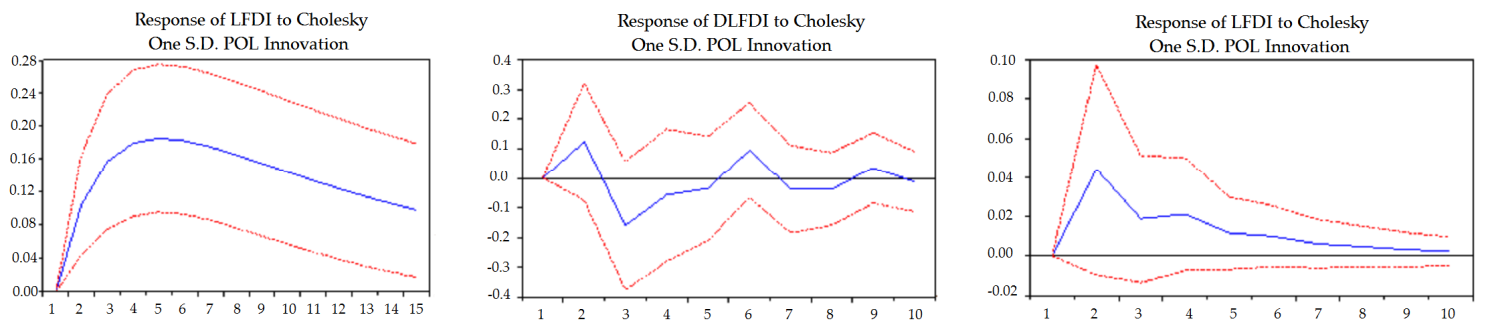

Figure 1. Impulse response of FDI to one standard deviation of political stability and the absence of violence/terrorism). Note: dotted red lines represent the +2 and -2 standard errors. From left to right, the charts represent the impulse response for panels A, B and C.
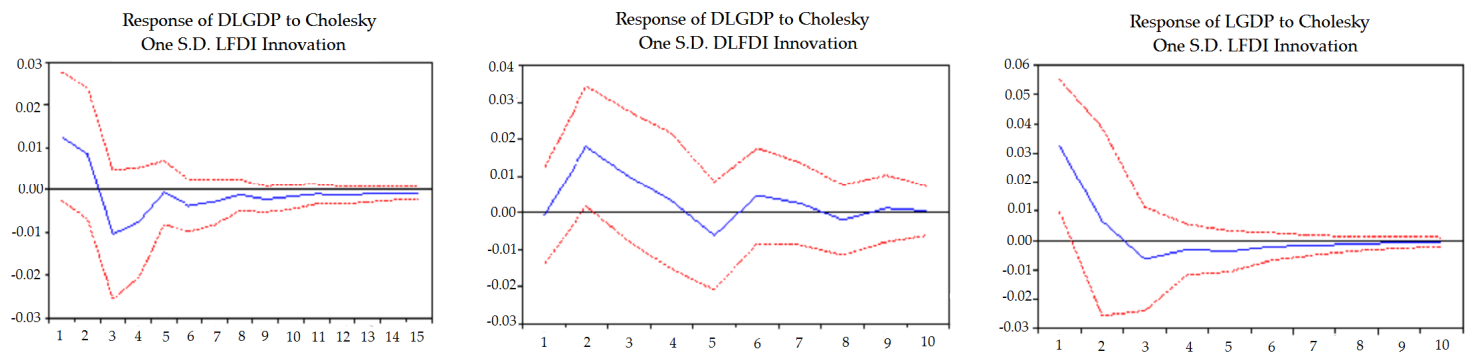

Figure 2. Impulse response of GDP to one standard deviation of FDI. Note: dotted red lines represent the +2 and -2 standard errors. From left to right, the charts represent the impulse response for panels A, B and C.

Similarly, with panel C, an initial positive response may be described as very close or equal to zero after three periods. Taking into account the Cholesky impulse response function and the Granger causality test, it seems we can strongly reject the presence of a bivariate relationship between FDI and GDP for panel C. There seems to be a strong initial response in panel B with a decreasing trend, which becomes negative after four responses, yet in a short span between six and eight responses, is once again positive. Conclusively, we fail to see the evidence of a long-term relationship in any of the three Cholesky impulse response functions and detect a significant short-term relationship only in panel B. The only regard in which the three panels displayed similar results is the response of FDI to one standard deviation of GDP. As expected for panel A, a slight increase becomes very close or equal to zero after four periods. There seems to be no significant impact at all for panel $\mathrm{C}$, as can be seen in Figure 3.
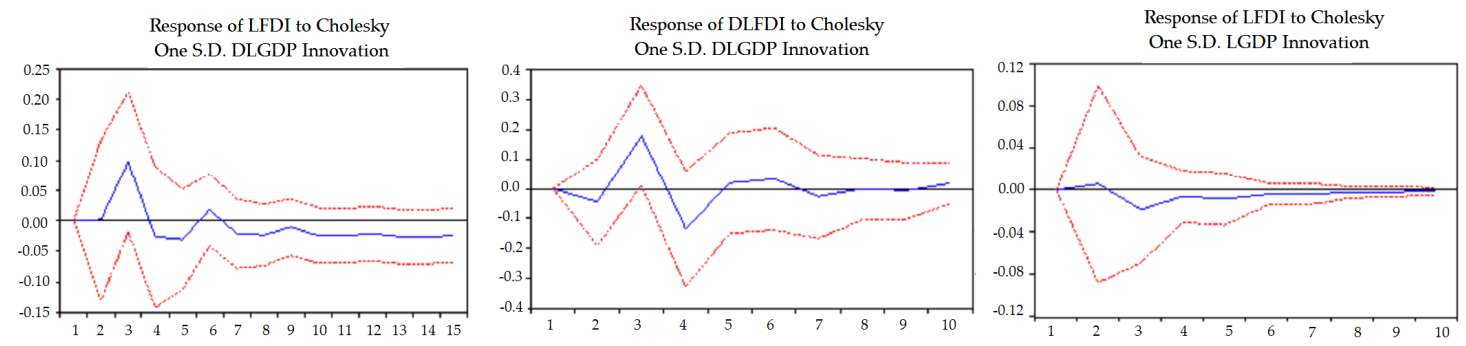

Figure 3. Impulse response of FDI to one standard deviation of GDP. Note: dotted red lines represent the +2 and -2 standard errors. From left to right, the charts represent the impulse response for panels $\mathrm{A}, \mathrm{B}$ and $\mathrm{C}$.

This is perhaps because these economies are constantly experiencing economic growth and hence an increase in their GDP does not really have a significant impact on further increasing investor confidence. The results for panel B also suggest that there seems to be no significant impact of an 
increase of one standard deviation of GDP on FDI, which after moderate fluctuations seems to have close to or equal zero effects after five periods. The results of the impulse response functions have significant similarities with the impulse response functions determined by Čičak and Sorić (2015). The overall results are conclusive with the studies performed by Büthe and Milner (2008) and results by those such as Aga (2014), which confirm that not all countries have a statistically significant long-term relationship between FDI and GDP.

\subsection{ARDL Analysis}

Based upon the results of the stationarity tests, it is possible to conclude that the ARDL analysis may be used on all countries except for St. Kitts and Nevis, and Antigua and Barbuda. There are also limitations when using it for the USA and Mexico. For the USA, we determine that GDP is I(2) and for Mexico we determine that political stability is $\mathrm{I}(2)$, meaning that we are unable to use the ARDL analysis on these countries. Full results of the unit root tests are available in Appendix A. We constructed the models with the number of lags suggested by the Akaike criterion. If the model displayed any kind of specification issue, such as serial correlation, heteroscedasticity or parameter instability, we re-estimated the model with the number of lags that would be second best in minimizing the value of the Akaike criterion. This procedure would be repeated until establishing a model free of any specification errors, although, in most models, the lag length automatically suggested by the Akaike criterion was deemed suitable.

None of the models exhibit serial correlation issues, fail to reject the null of heteroscedasticity, and have parameter stability based upon the CUSUM test. The tests for heteroscedasticity and serial correlation are presented in Appendix A. By conducting a Bounds test, we find that for the majority of countries from panel $\mathrm{A}$, we may reject the null hypothesis of no long-running relationship for both models. For all of the countries of panel B, we failed to reject the null hypothesis of no long-run relationship at the 5\% significance level both between FDI and GDP and between political stability and FDI. For panel C, we fail to reject the null of no long-run relationship between political stability and FDI, but we strongly reject the null hypothesis regarding no long-run relationship between FDI and GDP. For all of the countries of panel C, except for Mexico, we reject it even at the $1 \%$ significance level, while, for Mexico, we reject it at the $2.5 \%$ significance level. Detailed results are presented in Table 4.

These findings mostly confirm the previous hypotheses presented based upon the Granger causality test and the VAR model. Most notably, we find strong empiric evidence that there is a long-running relationship between political stability and FDI in smaller economies, while, for larger and more developed economies, we find no evidence of such a relationship. The only difference between these findings and our previous findings is determining long-running relationships between FDI and GDP for panel C countries, which we failed to determine based upon the Cholesky impulse response function. We provide long run coefficients for both ARDL models when they rejected the null hypothesis of no long-running relationship.

As it is possible to view in Table 5, in the majority of occurrences the coefficients are not statistically significant, but that does not undermine the overall hypothesis of statistically significant long-term relationship, as the overall explanatory value of the model is very high and the specification tests indicate that the models are adequate. We find that for countries from panel $\mathrm{C}$, the only long-term positive coefficients were for the models where GDP was the dependent variable and FDI the independent variable. In panel A, we note two instances of statistically significant positive coefficients for political stability in a panel when FDI was the dependent variable and political stability the independent variable. This conclusion overall conforms to our previous conclusion from the Granger causality test and the VAR analysis. These findings are especially interesting in light of Haksoon (2010) hypothesis that FDI inflows are high in politically unstable countries. These results seem to confirm his hypothesis, as well as suggest that FDI has a long-term positive relationship with economic growth in politically less stable countries rather than in more politically stable economies. Similarly, as Jadhav (2012) who failed to find empiric evidence that political stability is relevant to FDI inflows for 
the BRICS countries, we fail to find empiric evidence of their long-term relevance to FDI inflows in all economies with the noted exception of panel A. This suggests that political stability is a precondition for investment into smaller and less developed countries, while investors are not concerned with instances of political violence or terrorism in larger and more developed economies. This confirms the alternative hypothesis we presented in the introduction and thus suggests that there is no evidence of a CNN effect in the panels of countries that we have observed.

Table 4. Bounds test for ARDL analysis.

\begin{tabular}{ccccc}
\hline Country & $\begin{array}{c}\text { GDP and FDI } \\
\text { ARDL Bounds Test }\end{array}$ & $\begin{array}{c}\text { Null Hypothesis of No } \\
\text { Long-Run Relationship }\end{array}$ & $\begin{array}{c}\text { FDI and POL ARDL } \\
\text { Bounds Test }\end{array}$ & $\begin{array}{c}\text { Null Hypothesis of No } \\
\text { Long-Run Relationship }\end{array}$ \\
\hline Seychelles & $12.88^{* * * *}$ & Rejected & $6.237^{* * * *}$ & Rejected \\
\hline Guinea-Bissau & 2.33 & Failed to reject & $6.467^{* * * *}$ & Rejected \\
\hline Lesotho & $5.021^{* * *}$ & Rejected & $38.865^{* * * *}$ & Rejected \\
\hline Burundi & $14.391^{* * * *}$ & Rejected & $5.016^{* * *}$ & Rejected \\
\hline Vanuatu & & & $5.37^{* * * *}$ & Rejected \\
\hline Dominica & $7.738^{* * * *}$ & Rejected & $3.56^{*}$ & Rejected \\
\hline $\begin{array}{c}\text { St. Vincent and the } \\
\text { Grenadines }\end{array}$ & $8.151^{* * * *}$ & Rejected & 1.63 & Failed to reject \\
\hline Grenada & 2.432 & Failed to reject & $3.214^{*}$ & Rejected \\
\hline St. Lucia & $8.037^{* * * *}$ & Rejected & 0.785 & Failed to reject \\
\hline UK & 1.276 & Failed to reject & 2.903 & Failed to reject \\
\hline Canada & 2.67 & Failed to reject & 2.8003 & Failed to reject \\
\hline Australia & 0.759 & Failed to reject & $3.112^{*}$ & Rejected \\
\hline USA & & & $4.0122^{* *}$ & Rejected \\
\hline France & 1.056 & Failed to reject & 0.747 & Failed to reject \\
\hline Turkey & $13.738^{* * * *}$ & Rejected & 2.956 & Failed to reject \\
\hline Russian Federation & $6.442^{* * * *}$ & Rejected & 0.763 & Failed to reject \\
\hline Israel & $11.39^{* * * *}$ & Rejected & 2.874 & Failed to reject \\
\hline Mexico & $4.402^{* * *}$ & Rejected & & \\
\hline Not & & $/$ & \\
\hline
\end{tabular}

Note: ${ }^{* * *}, * *$ and ${ }^{* * * *}$ indicate statistical significance at the respected $0.1,0.05,0.025$ and 0.01 levels of significance.

Table 5. FDI and POL long run coefficients.

\begin{tabular}{ccc}
\hline Country & FDI Long Run Coefficient & POL Long Run Coefficient \\
\hline Seychelles & $-1.18^{* * *}(0.0001)$ & $-1.717(0.1049)$ \\
Guinea-Bissau & $/$ & $7.84(0.1432)$ \\
Lesotho & $0.1003(0.4456)$ & $-0.696(0.3738)$ \\
Burundi & $-0.009(0.7238)$ & $1.835^{* *}(0.028)$ \\
Vanuatu & $/$ & $2.39^{* *}(0.0308)$ \\
Dominica & $1.106(0.1539)$ & $0.098(0.8642)$ \\
St. Vincent and the Grenadines & $-0.224(0.2259)$ & $/$ \\
Grenada & $/$ & $0.691(0.295)$ \\
St. Lucia & $0.278(0.1519)$ & $/$ \\
UK & $/$ & $/$ \\
Canada & & \\
Australia & & \\
USA & & \\
\hline France & & \\
\hline Turkey & $0.464(0.7219)$ \\
Russian Federation & $0.3304^{* * *}(0.0000)$ & \\
Israel & $1.003^{* * *}(0.0093)$ & \\
Mexico & $0.123^{* *}(0.0139)$ & \\
\hline
\end{tabular}

Note: values in the parenthesis represent the $p$ value. ${ }^{*}, * *$ and ${ }^{* * *}$ indicate statistical significance at the respected 0.1 , 0.05 , and 0.01 levels of significance. 


\section{Conclusions}

We conducted a three-step empiric approach to primarily determining the relevance of FDI to GDP and of political stability to FDI. Based upon the conducted quantitative analysis methods, it is possible to conclude that there is a significant difference in the significance of political stability in countries based upon their respected economic size and levels of development. In our analysis, we determine that political stability is only relevant to FDI in the panel of smallest economies, while we find no such causality in larger economies. We further determine, based upon the VAR analysis, that the relationship between political stability and FDI is relevant both in the short term and in the long term for the small economies in panel A, while we find limited evidence of relevance of political stability towards increasing FDI in the short term for panels B and C. We did not find any empirical evidence of significant difference between developed larger economies that have a higher level of political stability in comparison to those that have occasional or even frequent episodes of political violence and/or terrorism regarding to the relevance of their political stability on FDI inflows.

This means that political stability is not a crucial factor in determining FDI inflows in highly developed or large, emerging economies studied. The empirical evidence seems to suggest that political violence and terrorist attacks do not have a statistically significant impact on investors and that although political stability is perceived as an initial condition necessary for starting investments in smaller economies, while there seems to be very few differences in that regard between the larger and more developed economies. This can further be applied to other developed countries and carries relevant policy recommendations. As can be seen, this paper fails to fully capture the relevance of all political aspects on economic growth, as it only considers political stability and the absence of violence. Clearly, the positive impact of FDI specifically for Mexico and the Russian Federation suggests that investors are prepared to take risks and prioritize ease of investment ahead of the actual political stability of the country. This largely conforms to the findings of Lucas (1990). This suggests that, due to the relevant "spillover" impact that FDI brings, that administrative barriers, redundant regulation and other barriers need to be removed in order to facilitate a more responsive climate for facilitating foreign investments. We largely find that Pandya (2016) conclusion of many barriers to investment being removed is correct, but we advocate the necessity of innovation and further investments into new technologies and investments are required in order to account for the increased costs of labor and production in more developed economies.

Acknowledgments: The authors have written the paper without any particular financial support. The authors would like to thank the Economies Journal for providing reviews of high quality and professional editorial work.

Author Contributions: Both authors wrote the paper, with Petar Kurečić focusing on the theoretical aspects and hypothesis construction and Filip Kokotović focusing on the empiric analysis.

Conflicts of Interest: The authors declare no conflict of interest.

\section{Appendix A}

As was mentioned in the methodological discussion, the full specification of the panels is presented in Table A1.

Table A1. Panel specification.

\begin{tabular}{cccc}
\hline Panel A & Panel A-Continued & Panel B & Panel C \\
\hline Seychelles & Burundi & Australia & Mexico \\
Guinea-Bissau & Vanuatu & Canada & Israel \\
Lesotho & St. Kitts and Nevis & France & Russian Federation \\
Dominica & St. Vincent and the Grenadines & United Kingdom & Turkey \\
Grenada & Antigua and Barbuda & United States & \\
St. Lucia & & & \\
\hline
\end{tabular}


Summary statistics are presented in Table A2, these statistics are of the variables in level and without any statistical transformations that were applied in order to ensure stationarity.

Table A2. Summary statistics.

\begin{tabular}{|c|c|c|c|c|c|c|c|c|c|}
\hline \multicolumn{2}{|c|}{ Variable } & Mean & Median & Maximum & Minimum & $\begin{array}{c}\text { Std. } \\
\text { Deviation }\end{array}$ & Skewness & Kurtosis & Observations \\
\hline \multirow[b]{2}{*}{ GDP } & Panel A & $1.22 \times 10^{9}$ & $8.64 \times 10^{8}$ & $9.50 \times 10^{9}$ & 4662335 & $1.16 \times 10^{9}$ & 3.145 & 24.916 & 373 \\
\hline & Panel B & $3.67 \times 10^{12}$ & $1.77 \times 10^{12}$ & $1.74 \times 10^{13}$ & $4.43 \times 10^{11}$ & $4.6 \times 10^{12}$ & 1.769 & 4.72 & 170 \\
\hline \multirow[b]{2}{*}{ FDI } & Panel A & 99575186 & 68421638 & $9.89 \times 10^{8}$ & 1093.496 & $1.22 \times 10^{8}$ & 4.023 & 24.916 & 363 \\
\hline & Panel B & $6.34 \times 10^{10}$ & $3.4 \times 10^{10}$ & $4.25 \times 10^{11}$ & $-3.36 \times 10^{10}$ & $8.49 \times 10^{10}$ & 2.332 & 8.16 & 170 \\
\hline \multirow[t]{2}{*}{ Export } & Panel B & $5.97 \times 10^{11}$ & $4.71 \times 10^{11}$ & $2.34 \times 10^{12}$ & $9.27 \times 10^{10}$ & $4.72 \times 10^{11}$ & 1.816 & 6.394 & 162 \\
\hline & Panel C & $1.69 \times 10^{13}$ & $3.91 \times 10^{11}$ & $2.36 \times 10^{14}$ & $4.59 \times 10^{10}$ & $5.04 \times 10^{13}$ & 3.364 & 13.247 & 120 \\
\hline \multirow{3}{*}{$\begin{array}{l}\text { Political } \\
\text { stability }\end{array}$} & Panel A & 0.424 & 0.81 & 1.42 & -2.51 & 0.895 & -1.6 & 4.77 & 172 \\
\hline & Panel B & 0.501 & 0.55 & 1.01 & -0.2 & 0.276 & -0.533 & 3.491 & 31 \\
\hline & Panel C & -0.539 & -0.68 & -0.1 & -0.8 & 0.249 & 0.714 & 1.888 & 15 \\
\hline \multirow[t]{2}{*}{ Area } & Panel B & 58114336 & 45112000 & $1.89 \times 10^{8}$ & 5651000 & 60940263 & 1.289 & 3.065 & 165 \\
\hline & Panel C & 35038522 & 22975000 & $1.32 \times 10^{8}$ & 285800 & 43234777 & 1.453 & 3.46 & 121 \\
\hline
\end{tabular}

As was previously mentioned, when testing Granger causality for FDI and GDP in panel C, we failed to obtain statistically significant consistent results. At one lag, we find a unidirectional causality going from FDI to GDP, at two lags, we find unidirectional causality going from GDP to FDI and the test results with three and more lags are displayed in Table A3.

Table A3. Granger causality between GDP and FDI for panel C.

\begin{tabular}{cccc}
\hline \multirow{2}{*}{ Null Hypothesis } & \multicolumn{3}{c}{ Test statistic Value } \\
\cline { 2 - 4 } & \multicolumn{1}{c}{$\mathbf{3}$ lags } & 4 lags & 5 lags \\
\hline GDP does not Granger cause FDI & $6.82^{* * *}(0.0003)$ & $5.554^{* * *}(0.0005)$ & $5.554^{* *}(0.0005)$ \\
FDI does not Granger cause GDP & $2.622^{*}(0.0546)$ & $0.679(0.6083)$ & $0.679(0.6083)$ \\
\hline
\end{tabular}

Note: values in the parenthesis represent the $p$ value. ${ }^{*}, * *$ and ${ }^{* * *}$ indicate statistical significance at the respected 0.1 , 0.05 and 0.01 levels of significance.

We confirm that no root lies outside the unit circle, as can be seen in Figure A1, meaning that the VAR models conform to the stability condition.

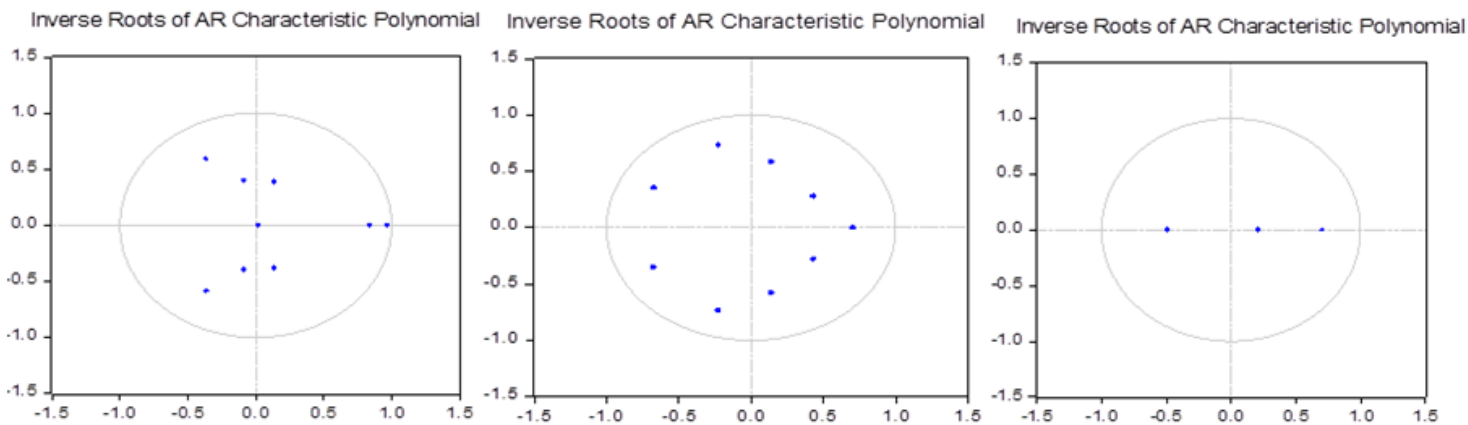

Figure A1. VAR model stability condition confirmation. Note: From left to right, the charts display the inverse roots of $\mathrm{AR}$ characteristic polynomial for panels $\mathrm{A}, \mathrm{B}$ and $\mathrm{C}$. 
We confirm that there is no autocorrelation present based upon the results of the LM test. The test results, summarized in Table A4, display that we fail to reject the null hypothesis of no autocorrelation.

Table A4. LM test for autocorrelation.

\begin{tabular}{cccc}
\hline Lags & Panel A LM-Stat & Panel B LM-Stat & Panel C LM-Stat \\
\hline 1 & $13.404(0.1452)$ & $13.49(0.1417)$ & $14.366(0.1099)$ \\
2 & $12.45(0.1891)$ & $10.71(0.2963)$ & $16.411(0.0518)$ \\
3 & $16.49(0.0513)$ & $9.458(0.3202)$ & $10.457(0.3147)$ \\
4 & $5.319(0.8056)$ & $9.459(0.3961)$ & $13.717(0.1327)$ \\
\hline
\end{tabular}

Note: values in the parenthesis represent the $p$ value.

As can be seen in Table A5, we conclude that for the majority of variables using the ARDL analysis is suitable. The ADF test uses the null hypothesis of no unit root, while the KPSS test null hypothesis is stationary. Therefore, rejection of the null hypothesis at any of the critical values based upon the KPSS test indicates the presence of a unit root. Using several unit root tests provides more certainty in interpreting the results, although the tests often have contradicting results. The KPSS test often gives a false confirmation of the stationary presence without viewing the first difference of the variable, which is why, in final interpretations, we often gave more value to the results of the ADF test.

Table A5. Unit root tests for ARDL analysis.

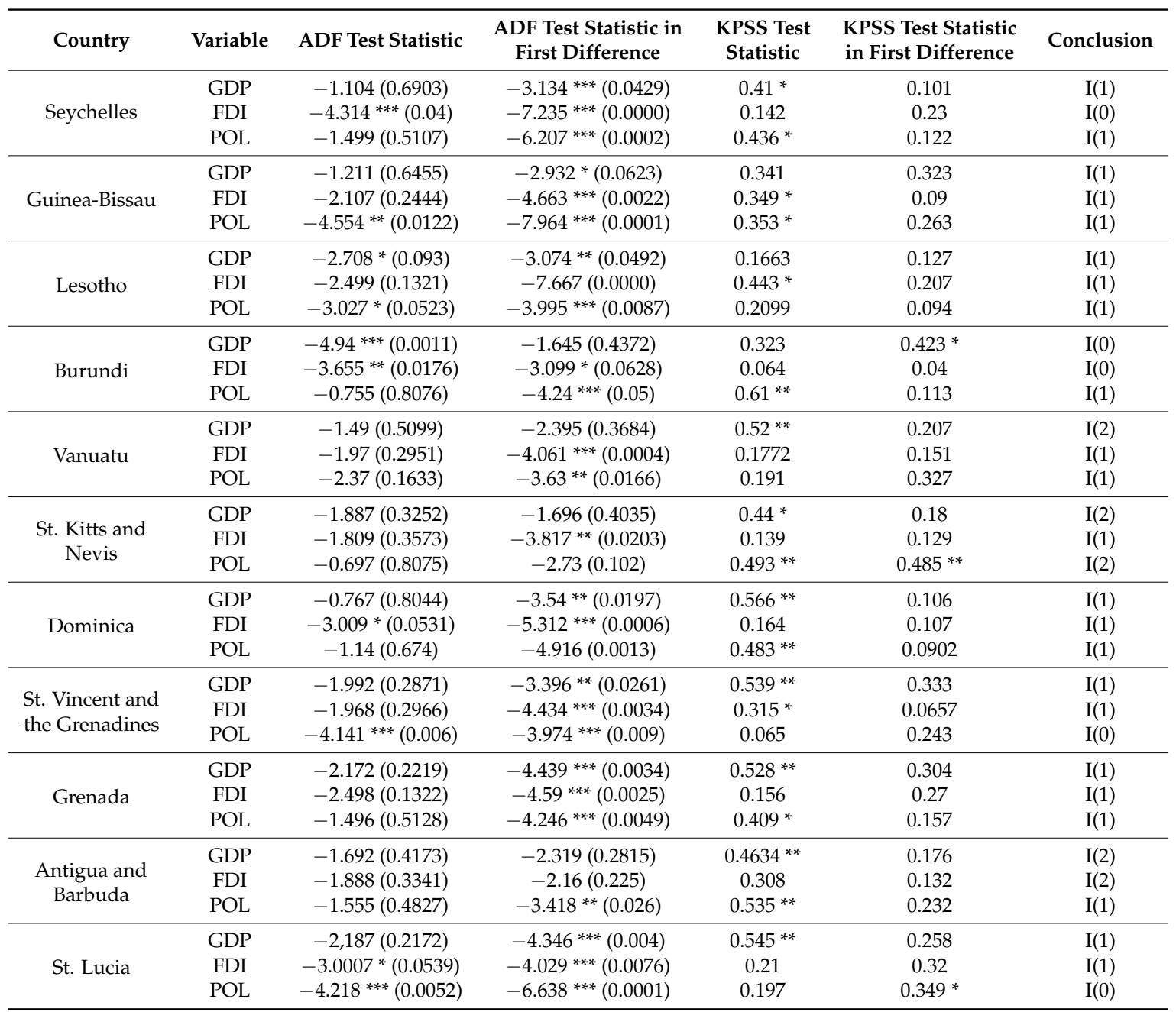


Table A5. Cont.

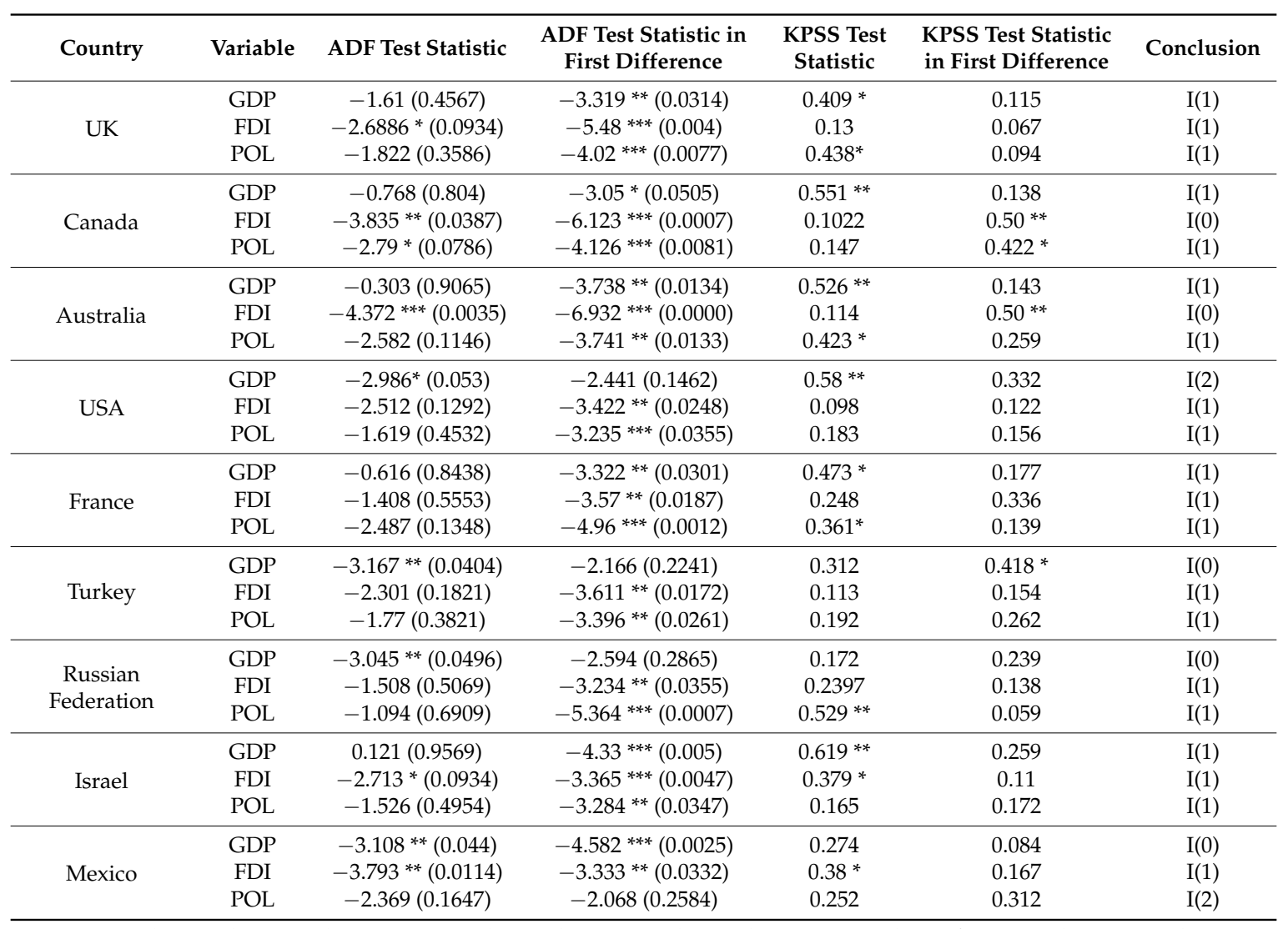

Note: values in the parenthesis represent the $p$ value. ${ }^{*}{ }^{* *}$ and ${ }^{* *}$ indicate statistical significance at the respected 0.1 , 0.05 , and 0.01 levels of significance.

Based upon the results in Tables A6 and A7, it is clear that all models do not exhibit any signs of serial correlation or heteroscedasticity.

Table A6. LM test for serial correlation.

\begin{tabular}{ccccc}
\hline Country & $\begin{array}{c}\text { LM Test Statistic } \\
\text { for GDP/FDI }\end{array}$ & $\begin{array}{c}\text { LM Observed } \\
\text { R-Squared for GDP/FDI }\end{array}$ & $\begin{array}{c}\text { LM Test Statistic } \\
\text { for FDI/POL }\end{array}$ & $\begin{array}{c}\text { LM Observed } \\
\text { R-Squared for FDI/POL }\end{array}$ \\
\hline Seychelles & $0.447(0.772)$ & $1.278(0.528)$ & $0.102(0.904)$ & $0.398(0.8196)$ \\
Guinea-Bissau & $1.787(0.2495)$ & $7.55(0.0563)$ & $1.917(0.2168)$ & $5.66(0.0589)$ \\
Lesotho & $0.2856(0.7612)$ & $1.304(0.521)$ & $0.206(0.8245)$ & $1.81(0.4044)$ \\
Burundi & $1.914(0.2173)$ & $5.3(0.0706)$ & $0.128(0.8842)$ & $1.103(0.5762)$ \\
Vanuatu & & & $0.8197(0.4638)$ & $2.164(0.339)$ \\
Dominica & $0.297(0.751)$ & $1.105(0.5754)$ & $0.125(0.8834)$ & $0.3401(0.8436)$ \\
Grenada & $0.271(0.7758)$ & $1.789(0.4089)$ & $0.915(0.4247)$ & $2.222(0.3292)$ \\
St. Lucia & $0.081(0.9228)$ & $0.396(0.8203)$ & $1.184(0.2685)$ & $4.246(0.1197)$ \\
UK & $0.313(0.7526)$ & $2.5895(0.274)$ & $0.822(0.4835)$ & $3.227(0.1992)$ \\
Canada & $0.16(0.6965)$ & $0.244(0.6211)$ & $0.9597(0.4762)$ & $5.852(0.0536)$ \\
Australia & $0.329(0.7258)$ & $0.866(0.6486)$ & $0.131(0.881)$ & $0.921(0.6311)$ \\
USA & $0.061(0.9407)$ & $0.168(0.9191)$ & $2.2086(0.1808)$ & $3.598(0.0579)$ \\
France & & & $0.597(0.5799)$ & $2.491(0.2878)$ \\
Turkey & $0.8667(0.4433)$ & $2.118(0.3469)$ & $0.101(0.9045)$ & $0.276(0.8712)$ \\
Ruscen & $0.0045(0.9955)$ & $0.012(0.9938)$ \\
Israel & $0.102(0.9034)$ & $0.279(0.8698)$ & $0.732(0.4996)$ & $1.823(0.402)$ \\
Mexico & $1.504(0.2955)$ & $5.008(0.0817)$ & $0.594(0.6759)$ & $5.44(0.0593)$ \\
\end{tabular}


Table A7. Heteroscedasticity test.

\begin{tabular}{ccccc}
\hline Country & $\begin{array}{c}\text { Heteroscedasticity } \\
\text { F-Statistic for } \\
\text { GDP/FDI }\end{array}$ & $\begin{array}{c}\text { Heteroscedasticity } \\
\text { Observed R-Squared for } \\
\text { GDP/FDI }\end{array}$ & $\begin{array}{c}\text { Heteroscedasticity } \\
\text { F-Statistic for } \\
\text { FDI/POL }\end{array}$ & $\begin{array}{c}\text { Heteroscedasticity } \\
\text { Observed R-Squared } \\
\text { for FDI/POL }\end{array}$ \\
\hline Seychelles & $0.629(0.6824)$ & $3.83(0.5745)$ & $1.23(0.3637)$ & $6.094(0.2972)$ \\
Guinea-Bissau & $0.654(0.6883)$ & $4.858(0.5622)$ & $0.486(0.746)$ & $2.37(0.668)$ \\
Lesotho & $1.173(0.4055)$ & $7.02(0.319)$ & $0.149(0.9929)$ & $3.167(0.9573)$ \\
Burundi & $0.309(0.8955)$ & $2.198(0.8212)$ & $0.688(0.6966)$ & $7.335(0.5009)$ \\
Vanuatu & & & $2.934(0.0701)$ & $6.948(0.0736)$ \\
Dominica & $0.3835(0.6879)$ & $0.8757(0.6454)$ & $0.072(0.9952)$ & $0.557(0.9899)$ \\
Grenada & $0.693(0.6924)$ & $7.204(0.5148)$ & $2.41(0.1236)$ & $4.379(0.112)$ \\
St. Lucia & $1.354(0.3366)$ & $7.558(0.2723)$ & $0.508(0.7877)$ & $4.138(0.658)$ \\
UK & $0.288(0.9496)$ & $5.121(0.8236)$ & $0.631(0.7039)$ & $4.8198(0.5671)$ \\
Canada & $2.528(0.0956)$ & $7.775(0.1002)$ & $0.584(0.7722)$ & $7.6895(0.5657)$ \\
Australia & $0.419(0.6654)$ & $0.952(0.6214)$ & $3.152(0.0896)$ & $12.117(0.1461)$ \\
USA & $0.315(0.7347)$ & $0.725(0.696)$ & $1.896(0.1975)$ & $8.807(0.1847)$ \\
France & & & $0.1606(0.9807)$ & $1.613(0.9517)$ \\
Turkey & $1.2557(0.3132)$ & $2.582(0.2751)$ & $2.248(0.140)$ & $4.1504(0.1255)$ \\
Vincent & $0.173(0.8431)$ & $0.405(0.8167)$ \\
Israel & $0.016(0.9842)$ & $0.038(0.981)$ & $0.032(0.9682)$ & $0.078(0.962)$ \\
Mexico & $1.338(0.3422)$ & $7.513(0.276)$ & $0.387(0.8823)$ & $6.98(0.6392)$ \\
& $2.647(0.1814)$ & $10.934(0.2054)$ & & $/$ \\
\hline
\end{tabular}

\section{References}

Aga, Ahmed Abdulrahman Khder. 2014. The Impact of Foreign Direct Investment on Economic Growth: A Case Study of Turkey 1980-2012. International Journal of Economics and Finance 6: 71-84.

Akaike, H. 1974. A new look at the statistical model identification. IEEE Transactions on Automatic Control 19: 716-23. [CrossRef]

Akande, Emmanuel, and Ola-David Oluyomi. 2010. The Two-Gap Model of Economic Growth in Nigeria: Vector Auto regression (VAR) Approach. Available online: https://www.gtap.agecon.purdue.edu/ resources/res_display.asp?RecordID=3225 (accessed on 28 April 2016).

Al-Eitan, Ghaith. 2013. A Dynamic Model for Determining Inward Foreign Direct Investment in Jordan. Perth: School of Economics and Finance, Curtin University.

Almfraji, Mohammad Amin, and Mahmoud Khalid Almsafir. 2014. Foreign Direct Investment and Economic Growth Literature Review from 1994 to 2012. Procedia-Social and Behavioral Sciences 129: 206-13. [CrossRef]

Asteriou, Dimitrios, Xeni Dassiou, and Dionysius Glycopantis. 2005. FDI and Growth: Evidence from a Panel of European Transition Countries. Spoudai 55: 9-30.

Bačić, Katarina, Domagoj Račić, and Amina Ahec-Šonje. 2004. The effects of FDI on recipient countries in Central and Eastern Europe. Privredna Kretanja i Ekonomska Politika 14: 59-96.

Balasubramanyam, Vudayagiri N., Mohammad Salisu, and David Sapsford. 1996. Foreign direct investment and growth in EP and IS countries. Economic Journal 106: 92-105. [CrossRef]

Barnard, George. 1959. Control charts and stochastic processes. Journal of the Royal Statistical Society 21: 239-71.

Bisson, Ourvashi. 2011. Can Better Institutions Attract More Foreign Direct Investment (FDI)? Evidence from Developing Countries. International Conference on Applied Economics. Available online: http://kastoria. teikoz.gr/icoae2/wordpress/wp-content/uploads/2011/10/007.pdf (accessed on 19 April 2016).

Brada, Josef C., Ali M. Kutan, and Taner M. Yigit. 2005. The Effects of Transition and Political Instability on Foreign Direct Investment in ECE Emerging Markets. New York: United Nations Documents Index.

Breusch, Trevor. 1978. Testing for Autocorrelation in Dynamic Linear Models. Australian Economic Papers 17: 334-55. [CrossRef]

Breusch, Trevor, and Adrian Pagan. 1979. A Simple Test for Heteroscedasticity and Random Coefficient Variation. Econometrica 47: 1287-94. [CrossRef]

Busse, Matthias, and Carsten Hefeker. 2005. Political Risk, Institutions and Foreign Direct Investment. Hamburgisches Welt-Wirtschafts-Archiv Discussion Paper 315. Available online: http://ageconsearch. umn.edu/bitstream/26388/1/dp050315.pdf (accessed on 19 April 2016).

Büthe, Tim, and Helen V. Milner. 2008. The Politics of Foreign Direct Investment into Developing Countries: Increasing FDI through International Trade Agreements? American Journal of Political Science 52: 741-62. [CrossRef] 
Čičak, Krešimir, and Petar Sorić. 2015. The Interrelationship of FDI and GDP in European Transition Countries. International Journal of Management Science and Business Administration 1: 41-58. [CrossRef]

Dickey, David A., and Wayne A. Fuller. 1979. Distribution of the Estimators for Autoregressive Time Series with a Unit Root. Journal of the American Statistical Association 74: 427-31. [CrossRef]

Elkomy, Shimaa, Hilary Ingham, and Robert Read. 2016. Economic and Political Determinants of the Effects of FDI on Growth in Transition and Developing Countries. Thunderbird International Business Review 58: 347-62. [CrossRef]

Gilboa, Eytan. 2005. The CNN Effect: The Search for a Communication Theory of International Relations. Political Communication 22: 27-44. [CrossRef]

Godfrey, Leslie G. 1978. Testing Against General Autoregressive and Moving Average Error Models when the Regressors Include Lagged Dependent Variables. Econometrica 46: 1293-301. [CrossRef]

Granger, Clive W.J. 1969. Investigating Causal Relations by Econometric Models and Cross-spectral Methods. Econometrica 37: 424-38. [CrossRef]

Haksoon, Kim. 2010. Political Stability and Foreign Direct Investment. International Journal of Economics and Finance 2: 59-71.

Iamsiraroj, Sasi, and Hristos Doucouliagos. 2015. Does Growth Attract FDI? Economics Journal. Available online: http:/ / www.economics-ejournal.org/economics/journalarticles/2015--19 (accessed on 28 April 2016).

Im, Kyung So, Mohammad Hashem Pesaran, and Yongcheol Shin. 2003. Testing for Unit Roots in Heterogeneous Panels. Journal of Econometrics 115: 53-74. [CrossRef]

Jadhav, Pravin. 2012. Determinants of foreign direct investment in BRICS economies: Analysis of economic, institutional and political factor. Procedia - Social and Behavioral Sciences 37: 5-14. [CrossRef]

Kaufmann, Daniel, Aart Kraay, and Massimo Mastruzzi. 2010. The Worldwide Governance Indicators: Methodology and Analytical Issues. Available online: www.govindicators.org (accessed on 19 April 2016).

Khan, Mashrur Mustaque, and Ibne Akbar Mashque. 2013. The Impact of Political Risk on Foreign Direct Investment. MPRA Paper No. 47283. Available online: http://mpra.ub.uni-muenchen.de/47283/ (accessed on 28 April 2016).

Kholdy, Shady. 1995. Causality between foreign investment and spillover efficiency. Applied Economics 27: 745-49. [CrossRef]

Krugman, Paul. 2009. The Return of Depression Economics and the Crisis of 2008. New York: Norton \& Company.

Kwiatkowski, Denis, Peter C. B. Phillips, Peter Schmidt, and Yongcheol Shin. 1992. Testing the null hypothesis of stationarity against the alternative of a unit root: How sure are we that economic time series have a unit root? Journal of Econometrics 54: 159-78. [CrossRef]

Levin, Andrew, Chien-Fu Lin, and Chia-Shang James Chu. 2002. Unit Root Tests in Panel Data: Asymptotic and finite-sample properties. Journal of Econometrics 108: 1-24. [CrossRef]

Livingston, Steven, and Todd Eachus. 1995. Humanitarian crises and U.S. foreign policy: Somalia and the CNN effect reconsidered. Political Communication 12: 413-29. [CrossRef]

Lucas, Robert E., Jr. 1990. Why does not Capital Flow from Rich to Poor Countries. American Economic Review 80: 92-6.

Maziarz, Mariusz. 2015. A review of the Granger-causality fallacy. The Journal of Philosophical Economics: Reflections on Economic and Social Issues 8: 86-105.

McMillan, Susan M. 1999. Foreign Direct Investment in Three Regions of the South at the End of the 20th Century. Basingstoke: McMillan Ltd.

Mehrara, Mohsen, Amin Haghnejad, Jalal Dehnavi, and Fereshteh Jandaghi Meybodi. 2010. Foreign Direct Investment, Exports, and Economic Growth in the Developing Countries: A Panel Data Approach. Journal of Academic Research in Economics 2: 259-80.

Onwuka, Kevin, and Kutlu Yasar Zoral. 2009. Foreign Direct Investment and Imports Growth in Turkey. Journal of Yasar University 4: 2357-80.

Page, E. S. 1954. Continuous Inspection Schemes. Biometrika 41: 100-15. [CrossRef]

Pandya, Sonal S. 2016. Political Economy of Foreign Direct Investment: Globalized Production in the Twenty-First Century. Annual Review of Political Science 19: 455-75. [CrossRef]

Pesaran, Mohammad Hashem H., Yongcheol Shin, and Richard J. Smith. 2001. Bounds Testing Approaches to the Analysis of Level Relationships. Journal of Applied Econometrics 16: 289-326. [CrossRef] 
Pesaran, Mohammad Hashem, and Yongcheol Shin. 1999. An Autoregressive Distributed Lag Modelling Approach to Cointegration Analysis. In Econometrics and Economic Theory in the 20th Century: The Ragnar Frisch Centennial Symposium. Edited by S. Strom. Cambridge: Cambridge University Press, chp. 11.

Phillips, Peter C., and Pierre Perron. 1988. Testing for a Unit Root in Time Series Regression. Biometrika 75: 335-46. [CrossRef]

Ray, Sarbapriya. 2012. Impact of Foreign Direct Investment on Economic Growth in India: A Co integration Analysis. Advances in Information Technology and Management 2: 187-201.

Robinson, Piers. 2005. The CNN Effect Revisited. Critical Studies in Media Communication 22: 344-9. [CrossRef]

Schwarz, Gideon. 1978. Estimating the Dimension of a Model. The Annals of Statistics 6: 461-4. [CrossRef]

Thakur, Ramesh. 2006. The United Nations, Peace and Security: From Collective Security to the Responsibility to Protect. Cambridge: Cambridge University Press.

Wooldridge, Jeffrey M. 2002. Econometric Analysis of Cross-Section and Panel Data. Cambridge: MIT Press.

World Bank. 2016. World Development Indicators. Available online: http://data.worldbank.org/ (accessed on 12 April 2016).

(C) 2017 by the authors. Licensee MDPI, Basel, Switzerland. This article is an open access article distributed under the terms and conditions of the Creative Commons Attribution (CC BY) license (http:/ / creativecommons.org/licenses/by/4.0/). 